\title{
Hydra-TH Extensions for Multispecies and Thermosolutal Convection
}

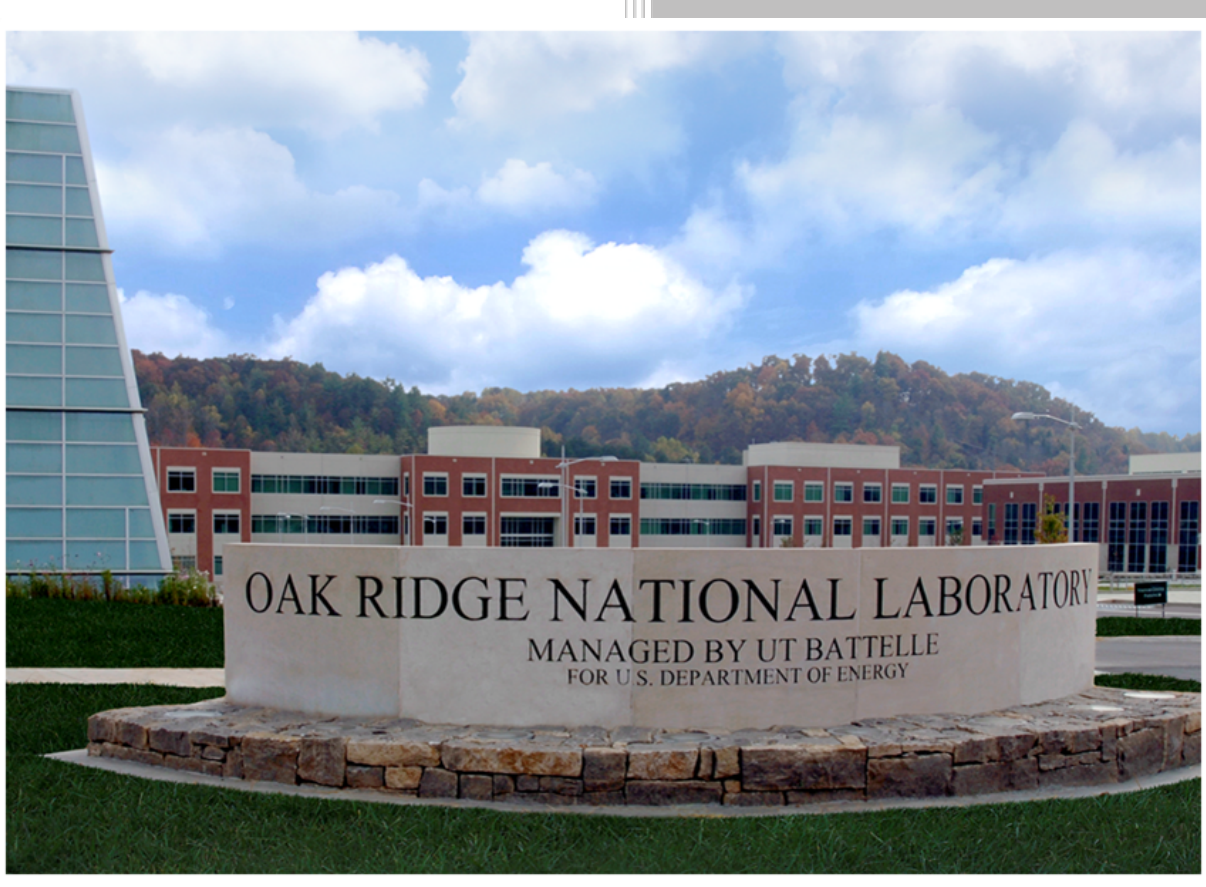

Alan K. Stagg

Su-Jong Yoon (Idaho National Laboratory)

September 2015 


\section{DOCUMENT AVAILABILITY}

Reports produced after January 1, 1996, are generally available free via US Department of Energy (DOE) SciTech Connect.

Website http://www.osti.gov/scitech/

Reports produced before January 1, 1996, may be purchased by members of the public from the following source:

National Technical Information Service

5285 Port Royal Road

Springfield, VA 22161

Telephone 703-605-6000 (1-800-553-6847)

TDD 703-487-4639

Fax 703-605-6900

E-mail info@ntis.gov

Website http://www.ntis.gov/help/ordermethods.aspx

Reports are available to DOE employees, DOE contractors, Energy Technology Data Exchange representatives, and International Nuclear Information System representatives from the following source:

Office of Scientific and Technical Information

PO Box 62

Oak Ridge, TN 37831

Telephone 865-576-8401

Fax 865-576-5728

E-mail reports@osti.gov

Website http://www.osti.gov/contact.html

This report was prepared as an account of work sponsored by an agency of the United States Government. Neither the United States Government nor any agency thereof, nor any of their employees, makes any warranty, express or implied, or assumes any legal liability or responsibility for the accuracy, completeness, or usefulness of any information, apparatus, product, or process disclosed, or represents that its use would not infringe privately owned rights. Reference herein to any specific commercial product, process, or service by trade name, trademark, manufacturer, or otherwise, does not necessarily constitute or imply its endorsement, recommendation, or favoring by the United States Government or any agency thereof. The views and opinions of authors expressed herein do not necessarily state or reflect those of the United States Government or any agency thereof. 
Consortium for Advanced Simulation of Light Water Reactors (CASL)

\title{
Hydra-TH Extensions for Multispecies and Thermosolutal Convection
}

\author{
Alan K. Stagg \\ Su-Jong Yoon
}

September 2015

Prepared by OAK RIDGE NATIONAL LABORATORY

Oak Ridge, TN 37831-6283

managed by

UT-BATTELLE, LLC

for the

US DEPARTMENT OF ENERGY

under contract DE-AC05-00OR22725 


\title{
Hydra-TH Extensions for Multispecies and Thermosolutal Convection (L3 Milestone THM.CFD.P11.02) \\ CASL-U-2015-0317-000
}

\author{
Alan K. Stagg \\ Modeling and Simulation Group \\ Computational Sciences and Engineering Division \\ Oak Ridge National Laboratory \\ Oak Ridge, TN 37831 \\ Su-Jong Yoon \\ Nuclear Systems Design and Analysis Division \\ Idaho National Laboratory \\ Idaho Falls, ID 83415
}

\section{Executive Summary}

This report describes the Consortium for Advanced Simulation of Light Water Reactors (CASL) work conducted for completion of the Thermal Hydraulics Methods (THM) Level 3 Milestone THM.CFD.P11.02: Hydra-TH Extensions for Multispecies and Thermosolutal Convection.

A critical requirement for modeling reactor thermal hydraulics is to account for species transport within the fluid. In particular, this capability is needed for modeling transport and diffusion of boric acid within water for emergency, reactivity-control scenarios. To support this need, a species transport capability has been implemented in Hydra-TH for binary systems (for example, solute within a solvent). A species transport equation is solved for the species (solute) mass fraction, and both thermal and solutal buoyancy effects are handled with specification of a Boussinesq body force. Species boundary conditions can be specified with a Dirichlet condition on mass fraction or a Neumann condition on diffusion flux. To enable enhanced species/fluid mixing in turbulent flow, the molecular diffusivity for the binary system is augmented with a turbulent diffusivity in the species transport calculation.

\section{Introduction}

The primary objective of this miletone is to implement a species transport capability within Hydra-TH, accounting for solutal and thermal buoyancy effects with specification of a Boussinesq force. Other objectives include verification of this capability with comparison of calculations to analytic solutions and documentation of the work and results.

The requirements specified at the project outset were:

- Species transport solver should provide expected diffusion solution in limit of no flow.

- Species transport solver without specification of Boussinesq force should provide scalar passive transport (tracer) solution.

- Mixing of two fluids with identical reference densities should result in zero buoyant force. 
- Specification of Dirichlet species mass fraction or Neumann diffusion flux boundary conditions.

- Specification of species mass fraction initial condition by global definition.

- Parallel

- Functional in both semi- and fully-implicit projection

- Enhanced species mixing in turbulent flow.

These requirements steered the design and subsequent implementation.

The milestone required completion of the following tasks:

- Development of a scalar passive transport capability for species mass fraction.

- Specification of species parameters in a manner consistent with existing material data structures.

- Implementation of a solutal buoyant force based on species mass fraction and consistent with existing thermal buoyant force.

- Selection and development of a thermosolutal test problem with addition to the regression test suite

- Development and application of user-defined species mass fraction boundary conditions for analytic test problem.

- User manual documentation

- Submission of this report

Some of these tasks are briefly discussed in $\S 3$, and a summary is given in $\S 4$.

\section{Milestone Accomplishments}

A species transport capability for binary systems has been developed in Hydra-TH for modeling the diffusional mixing and transport of a single species within a specified medium, e.g., boric acid within water. The following mass conservation equation is solved for a single species

$$
\rho \frac{\partial Z_{1}}{\partial t}+\rho \mathbf{v} \cdot \nabla Z_{1}=-\nabla J_{1}
$$

where $Z_{1}$ is the species mass fraction and $J_{1}$ is the species diffusion flux. Fick's law of diffusion is utilized with $J_{1}=-\rho D \nabla Z_{1}$, where $\rho$ is fluid density and $D$ is the scalar diffusivity for the binary system. In this implementation, species mass fraction and diffusion flux boundary conditions can be applied. In addition, user-defined or preprogrammed boundary conditions can be utilized for species mass fraction, and a global initial condition can be specified as well.

Activation of species transport in the control file is illustrated in Figure 1. In this example, an additional material block is used to prescribe species information. Note that this species material is not specified in the materialset block. In the case of scalar passive transport, 
the only species information required is the diffusivity for the binary system. For output of species mass fraction, both element and node centering are available as shown.

Solutal transport is enabled by adding a Boussinesq force to the species transport case as illustrated in Figure 2. The force term requires the species reference density (pure material), solutal expansion coefficient $\left(\beta_{s}\right)$, and species reference concentration, which have been added to the species material in the example. The species reference density and local mass fraction are used to calculate the local species concentration, and where this calculated species concentration is greater or less than the species reference concentration, a negative or positive buoyant force results.

Additionally, if the energy equation is activated, then thermosolutal effects are modeled. The sign conventions for the thermal expansion coefficient $(\beta)$ and the solutal expansion coefficient $\left(\beta_{s}\right)$ are consistent, with

$$
\begin{aligned}
& \beta=-\frac{1}{\rho}\left(\frac{\partial \rho}{\partial T}\right)_{P, C} \\
& \beta_{s}=-\frac{1}{\rho}\left(\frac{\partial \rho}{\partial C}\right)_{P, T}
\end{aligned}
$$

where $\beta$ and $\beta_{s}$ are the thermal and solutal expansion coefficients, and $P, T$, and $C$ are pressure, temperature, and species concentration (species mass divided by mixture volume), respectively. With this definition, the solutal expansion coefficient is positive when addition of species (solute) to background material (solvent) results in decreasing mixture density. When heavy solute is added to light solvent, the solutal expansion coefficient must be specified as negative.

For turbulent flow, the binary system diffusivity that appears in the species mass fraction transport equation is augmented by adding a turbulent diffusivity $D_{t}$ to the molecular diffusivity $D_{m}$. The effective diffusivity is defined as $D=D_{m}+D_{t}$, where $D_{t}=\frac{\nu_{t}}{S c_{t}}$, and $\nu_{t}$ and $S c_{t}$ are the eddy viscosity and turbulent Schmidt number, respectively. This approach is equivalent to a gradient diffusion approximation. The construction of the effective diffusivity is automatic when a turbulence model is activated, and control file activation is not required.

In addition, the augmentation of turbulent kinetic energy due to solutal (and thermal) effects is automatically handled when the RNG $k-\varepsilon$ model is utilized. The added thermal and solutal turbulent kinetic energy source terms are given by

$$
\begin{aligned}
G_{b, \text { thermal }} & =\beta g_{i} \frac{\mu_{t}}{P r_{t}} \frac{\partial T}{\partial x_{i}} \\
G_{b, \text { solutal }} & =\beta_{s} g_{i} \frac{\mu_{t}}{S c_{t}} \frac{\partial C}{\partial x_{i}}
\end{aligned}
$$

Note that turbulent kinetic energy is augmented in unstable stratification $\left(G_{b, *}>0\right)$.

Implemented capabilities are demonstrated with comparison to a problem with analytical solution. The thermosolutal convection example is based on a natural convection similarity solution for steady, laminar flow induced by a vertical, heated, flat plate $[1,2]$. The plate is immersed in an infinitely large body of fluid of constant properties, with only density variations considered in the body force terms. The equations of motion are cast in similarity form as

$$
\begin{gathered}
F^{\prime \prime \prime}+3 F F^{\prime \prime}-2\left(F^{\prime}\right)^{2}+\theta=0 \\
\theta^{\prime \prime}+3 \operatorname{Pr} F \theta^{\prime}=0
\end{gathered}
$$


with boundary conditions of

$$
\begin{aligned}
F^{\prime}(0) & =F^{\prime}(\infty)=\theta(\infty)=0 \\
F(0) & =0 \\
\theta(0) & =1
\end{aligned}
$$

where the similarity variable is

$$
\eta=x c / y^{1 / 4}
$$

and the stream function $\psi$ and forcing function $\theta$ are given by

$$
\begin{gathered}
\psi=4 \nu c y^{3 / 4} F(\eta) \\
\theta=\frac{\rho_{\infty}-\rho}{\left|\rho_{\infty}-\rho_{w}\right|}
\end{gathered}
$$

and

$$
c^{4}=\frac{g\left|\rho_{\infty}-\rho_{w}\right|}{4 \nu_{\infty}^{2} \rho_{\infty}}
$$

where $x$ is the coordinate normal to the plate, $y$ is the coordinate along the plate (vertical direction), and gravity acts in the negative $y$ direction. The velocity components are obtained from

$$
\begin{aligned}
& u=\nu c / y^{1 / 4}\left[\eta F^{\prime}-3 F\right] \\
& v=4 \nu c^{2} y^{1 / 2} F^{\prime}(\eta)
\end{aligned}
$$

The forcing function $\theta$ can be generated by a density dependence on temperature, a density dependence on species concentration, or a combination of both. For the thermal problem,

$$
\begin{aligned}
\theta & =\frac{T-T_{\infty}}{\left|T_{w}-T_{\infty}\right|} \\
c^{4} & =\frac{g \beta\left|T_{w}-T_{\infty}\right|}{4 \nu_{\infty}^{2}}
\end{aligned}
$$

and for the solutal transport problem,

$$
\begin{aligned}
\theta & =\frac{C-C_{\infty}}{\left|C_{w}-C_{\infty}\right|} \\
c^{4} & =\frac{g \beta_{s}\left|C_{w}-C_{\infty}\right|}{4 \nu_{\infty}^{2}}
\end{aligned}
$$

where $T$ is temperature, $C$ is species concentration, and $\beta$ and $\beta_{s}$ are the thermal and solutal expansion coefficients, respectively. The solutal transport problem that is analogous to the heated plate involves the specification of a species mass fraction value of unity on the vertical plate and value of zero at infinity, where the species reference density is lower than the fluid density.

The test problem defined here involves equal and additive contributions from thermal and solutal effects (equal thermal and solutal Rayleigh numbers, with $R a_{t} \approx 28,000$ ). In addition, the Lewis number is selected to be unity so that thermal and molecular diffusivities are equal. The problem setup is shown in the control file in Figure 3. The left and right 
vertical boundaries are located at $x=0$ and $x=0.575$, and the lower and upper horizontal boundaries are located at $y=1$ and $y=2$, respectively, so that $\eta$ ranges from 0 along the vertical plate to a value of 6.25 at the lower right-hand corner. User-defined boundary conditions for the lower, upper, and right boundaries have been constructed for velocity, temperature, and species mass fraction based on Equations $(13,14,16)$, respectively. These functions are developed from tabulated values of $F, \theta$, and their derivatives found in [2].

Velocity magnitude contours from the Hydra-TH calculation $(\operatorname{Pr}=1)$ are shown in Figure 4. The velocity achieves a maximum near the plate and approaches ambient conditions far from the plate, where fluid particles approach perpendicularly before turning tangentially along the plate. The decreased density due to near-plate heating and species presence leads to fluid acceleration in the vertical direction as observed in the figure.

Comparisons to the analytic solution for vertical velocity component ( $y$ direction), temperature, and species mass fraction are provided in Figures 5-7, respectively, near the upper boundary at $y=1.9$. Agreement is excellent. Note that the temperature and mass fraction profiles are identical for this problem with equal thermal and molecular diffusivities.

\section{Summary}

A species transport capability incorporating thermosolutal buoyancy effects has been developed within Hydra-TH for transport of a single species within a background fluid material.

A natural convection similary test problem was selected to verify correct implementation of code capabilities. The problem is unique in that it tests combined thermal and solutal buoyancy effects. Comparison of Hydra-TH calculations to the analytic solution yielded excellent agreement.

Although code capabilities have been implemented and tests conducted for laminar flow, additional testing is needed for turbulent thermosolutal convection. In addition, validation calculations are needed to test thermosolutal behavior in realistic reactor configurations.

This research was supported by the Consortium for Advanced Simulation of Light Water Reactors (www.casl.gov), an Energy Innovation Hub (http://www.energy.gov/hubs) for Modeling and Simulation of Nuclear Reactors under U.S. Department of Energy Contract No. DE-AC05-00OR22725.

\section{References}

[1] L. C. Burmeister, Convective Heat Transfer, John Wiley and Sons, Inc., 1983.

[2] S. Ostrach, An analysis of laminar free-convection flow and heat transfer about a plate parallel to the direction of the generating body force, Tech. Rep. 1111, NACA, 1953. 


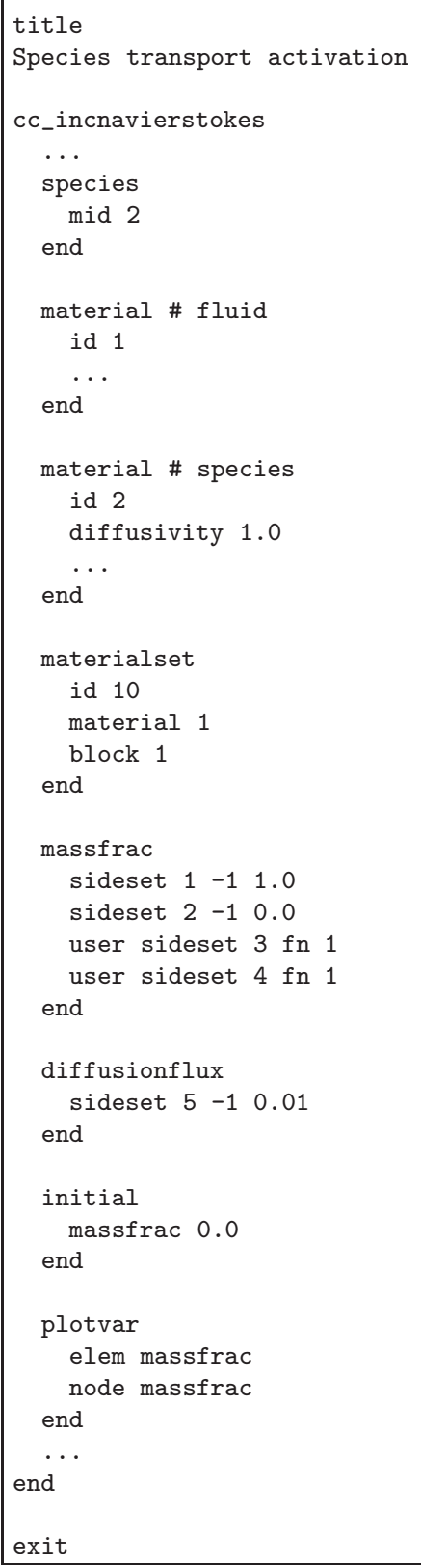

Figure 1: Species Transport Specification in Control File 


\begin{tabular}{|l|} 
title \\
Thermosolutal transport activation \\
cc_incnavierstokes \\
$\ldots$ \\
energy temperature \\
species \\
mid 2 \\
end \\
boussinesqforce \\
gx 0.0 \\
gy -9.8 \\
gz 0.0 \\
end \\
material \# fluid \\
id 1 \\
rho 958.4 \\
mu $2.82 \mathrm{e}-4$ \\
Cp $2.41 \mathrm{e}+3$ \\
k11 0.679 \\
beta $1.24 \mathrm{e}-11$ \\
Tref 300.0 \\
end \\
material \# species \\
id 2 \\
rho 862.56 \\
solutal_beta $2.86 \mathrm{e}-13$ \\
diffusivity $2.94 \mathrm{e}-7$ \\
Cref 0.0 \\
end \\
$\ldots$ \\
end \\
exit \\
\\
\\
\end{tabular}

Figure 2: Thermosolutal Transport Specification in Control File 


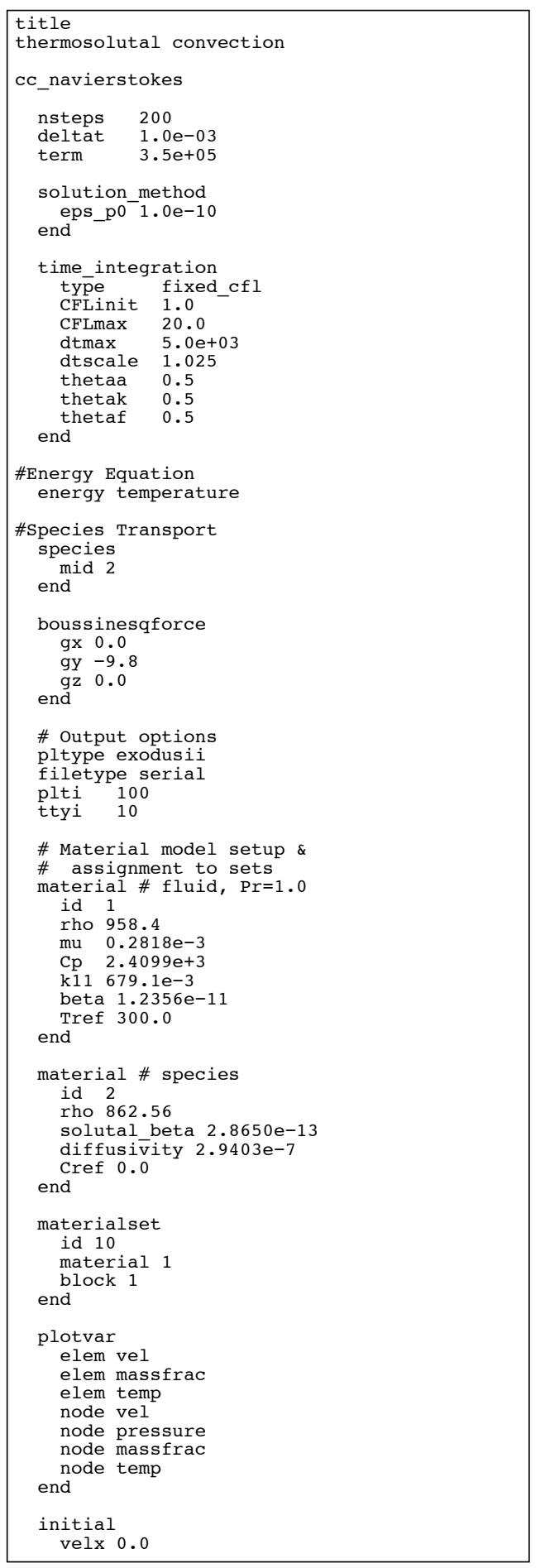

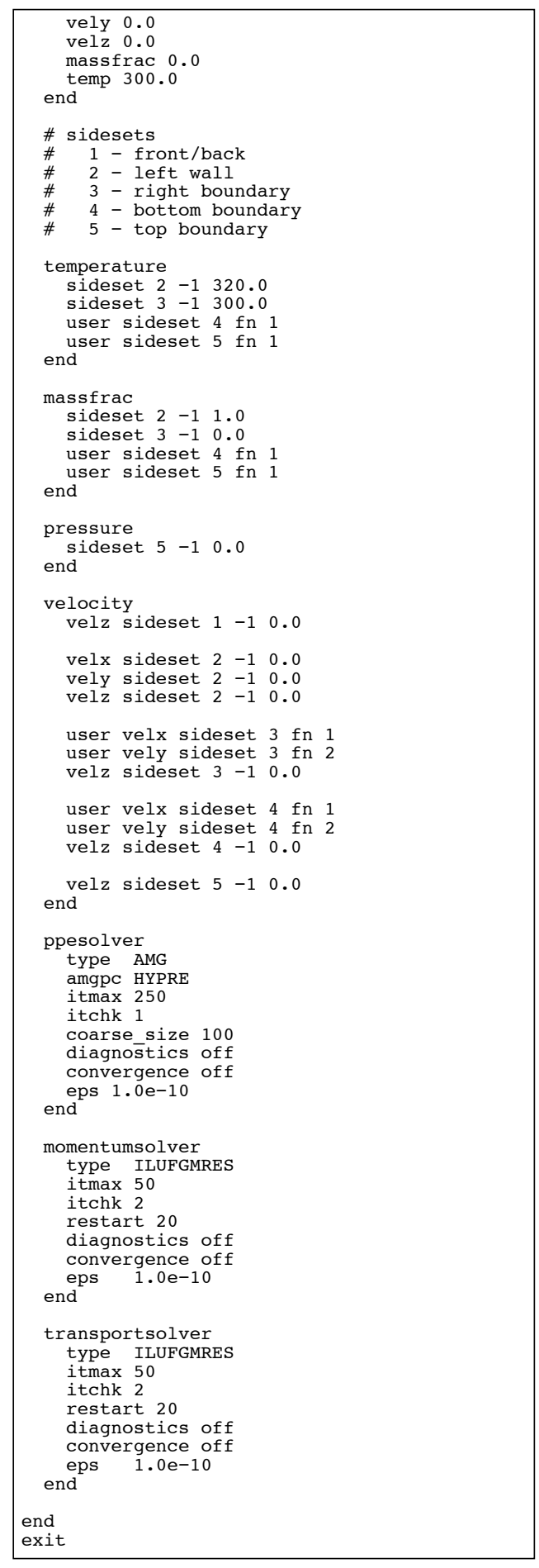

Figure 3: Thermosolutal Convection Control File 


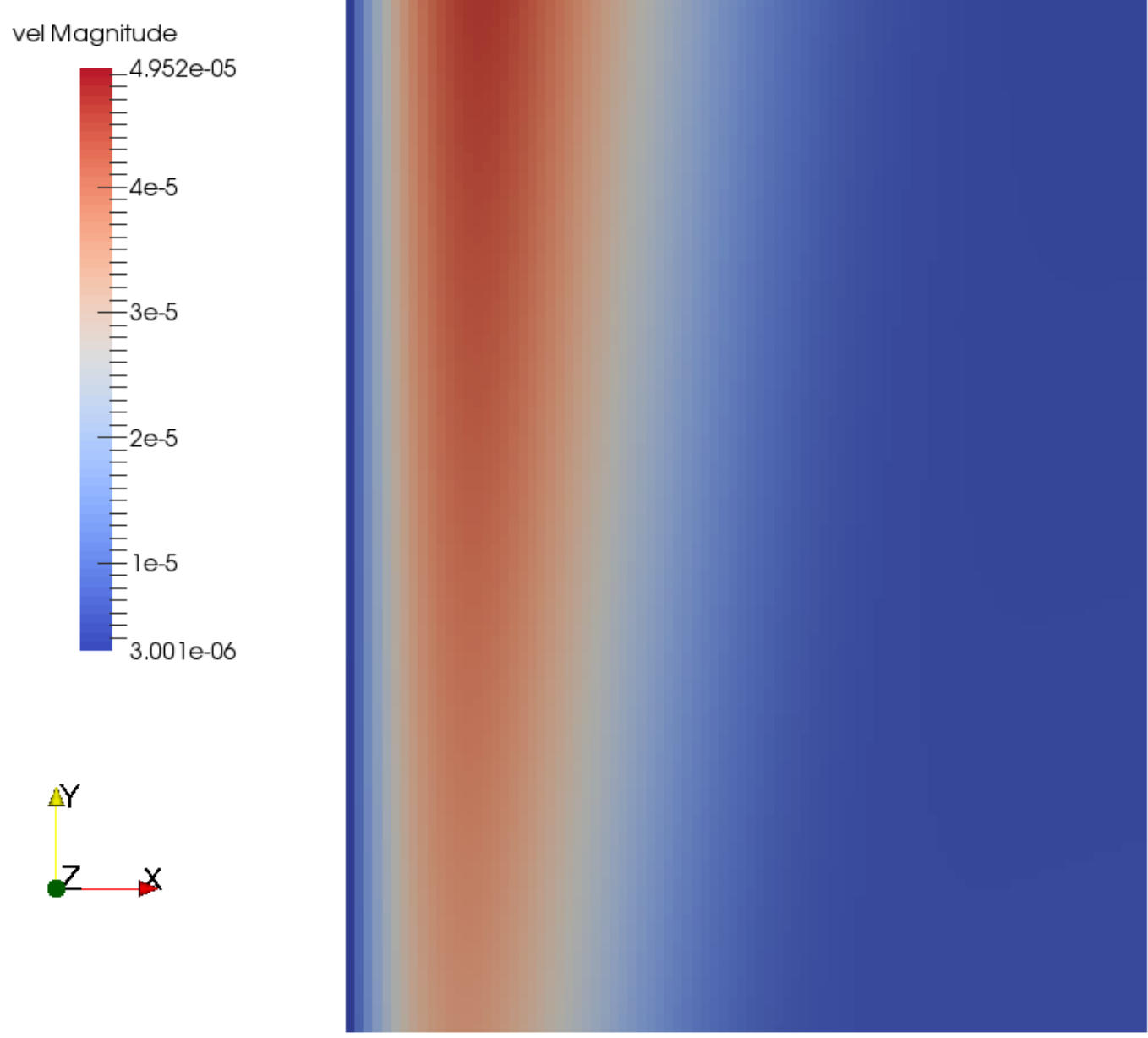

Figure 4: Velocity Magnitude Contours in Thermosolutal Similarity Test Problem 


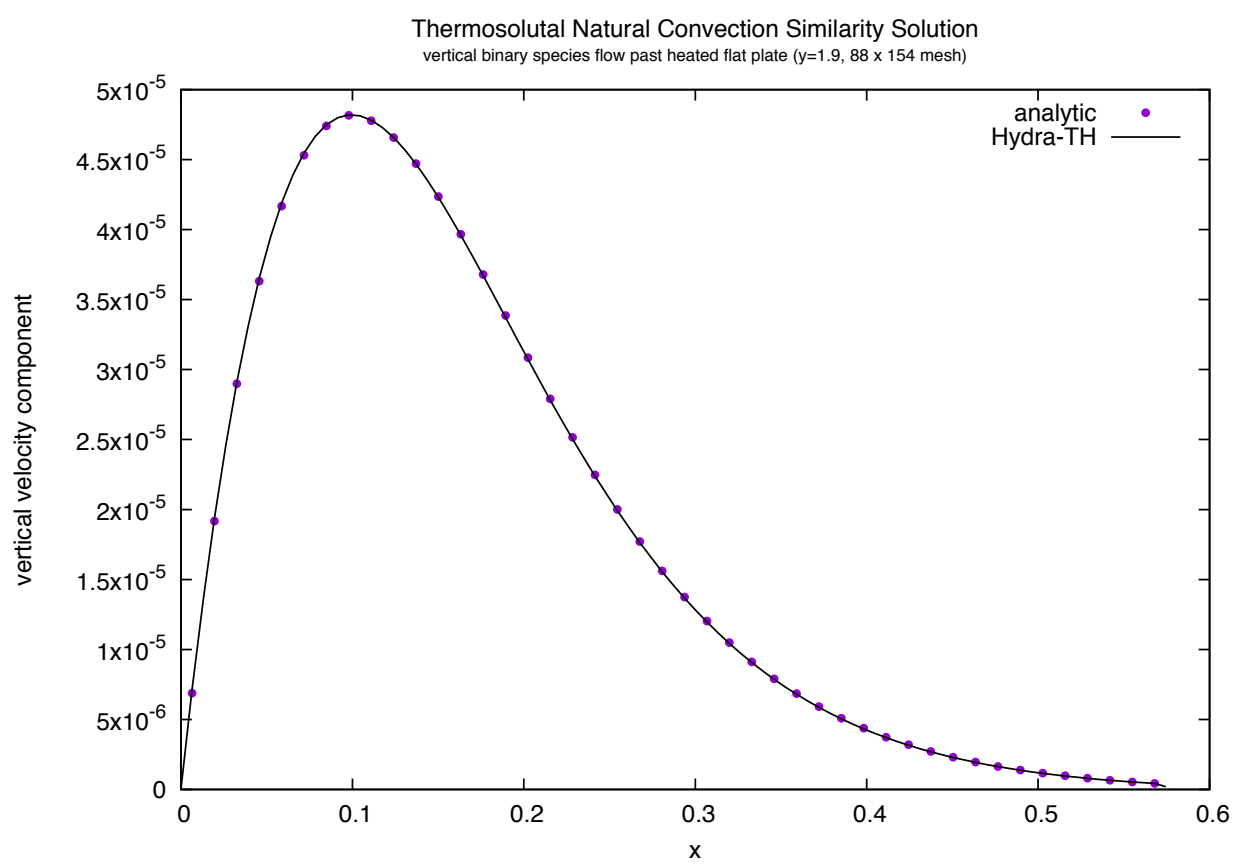

Figure 5: Hydra-TH Comparison to Analytic Solution (velocity)

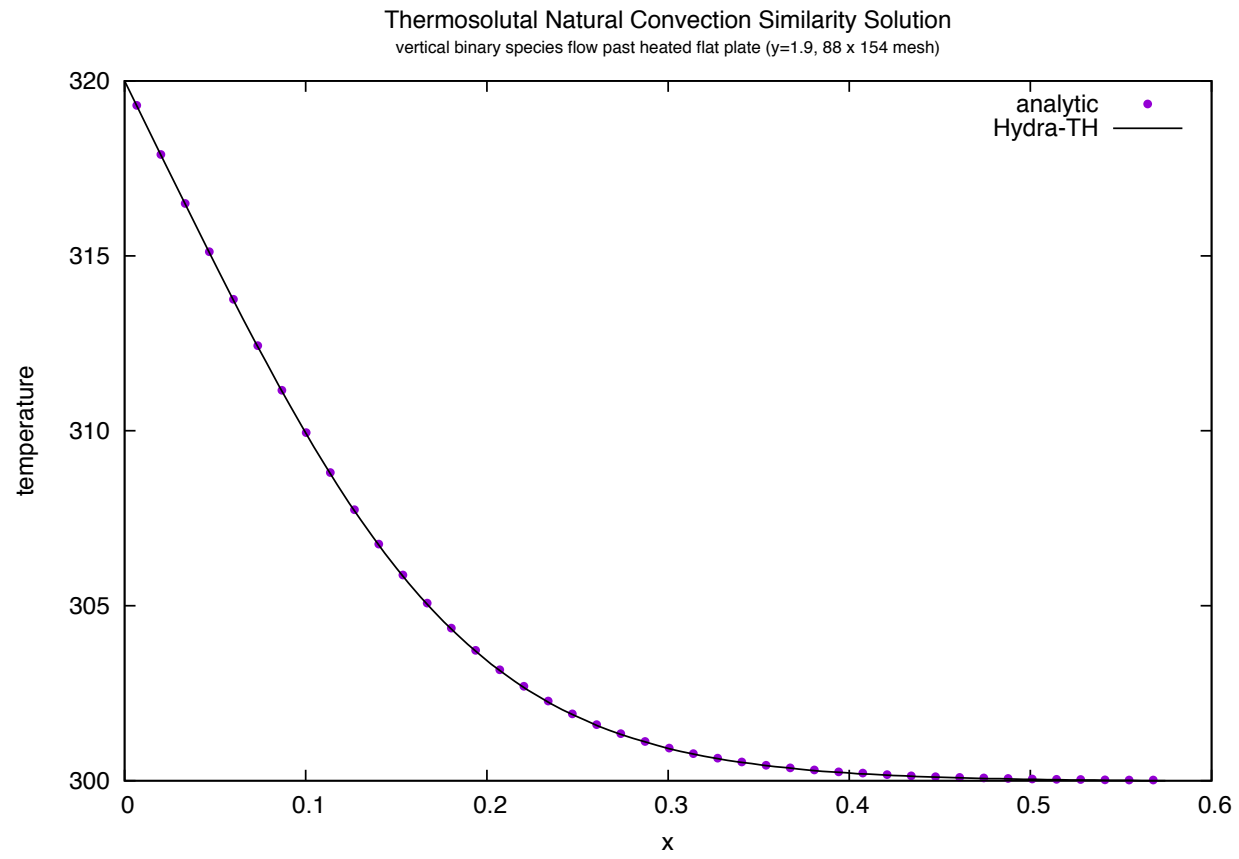

Figure 6: Hydra-TH Comparison to Analytic Solution (temperature) 


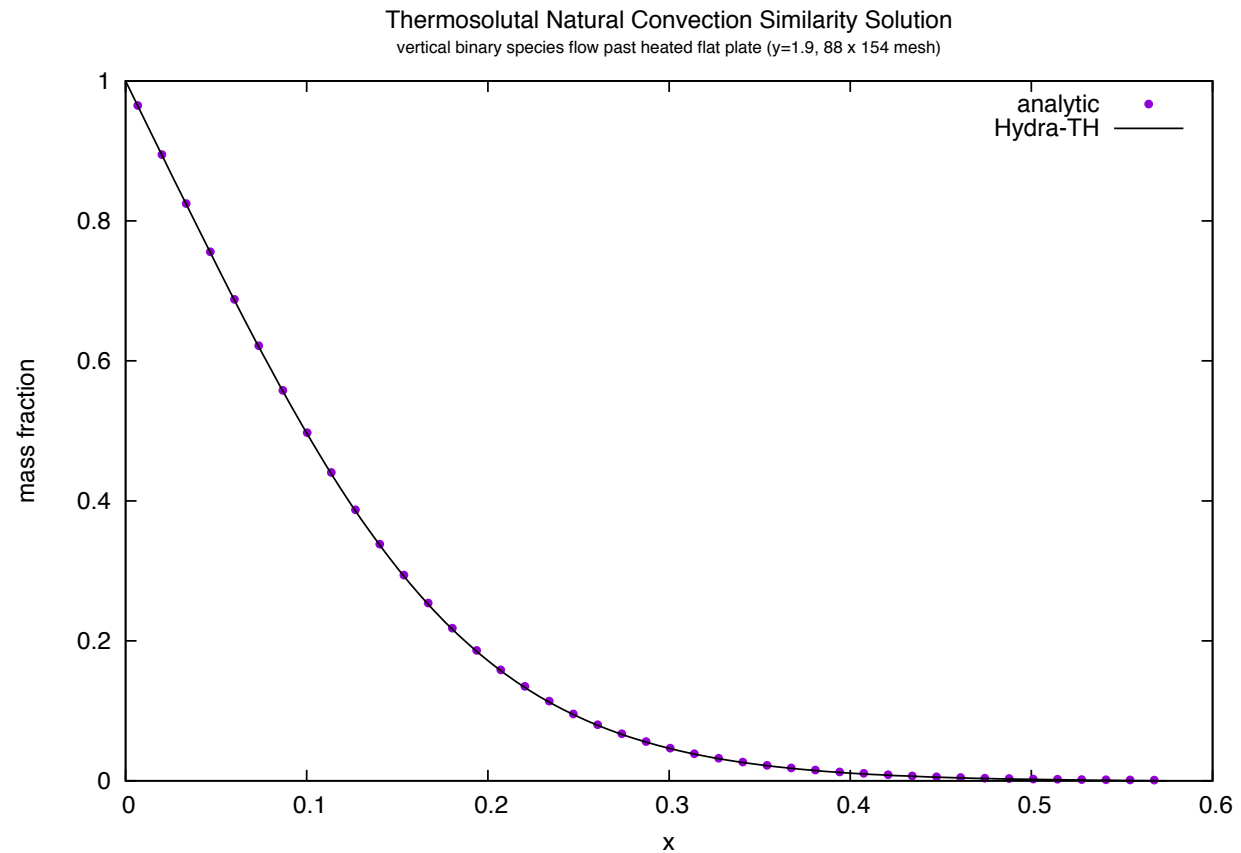

Figure 7: Hydra-TH Comparison to Analytic Solution (species mass fraction) 